\title{
BENCHMARK ANALYSIS FOR RECYCLED GLASS IN AUSTRIAN WASTE MANAGEMENT
}

\section{Karl Friedrich *, Stephan Holzschuster, Theresa Fritz, Roland Pomberger and Alexia Aldrian}

Montanuniversitaet Leoben, Department of Environmental and Energy Process Engineering, Chair of Waste Processing Technology and Waste Management, Franz-Josef-Straße 18, A-8700, Leoben, Austria

Article Info:

Received:

27 February 2020

Revised:

16 August 2020

Accepted:

17 September 2020

Available online:

28 December 2020

Keywords:

Recyclates

Cullets

Quality

Price

Correlation

\begin{abstract}
The amendment of the Waste Framework Directive of the European Commission has set a new target for the use of recyclates. It is one of the most significant findings of this strategy that recyclates are currently too infrequently integrated into new products. Glass recycling, however, is widely accepted by the society. The chemical and physical properties of glass enable an almost $100 \%$ rate of recycling. Furthermore, the society is experienced in separating glass by colour, resulting in high-quality recycling glass for the production of new glass. Cullets are significant here. Evidently, the price of recyclates is linked to the price of primary material. Practical experience has shown, however, that pricing also correlates with different quality parameters such as degree of mixing, degree of degradation and presence of impurities. This paper examines the correlation between different quality features, how they affect the price of cullets and which quality is seen as benchmark quality for the Austrian glass industry. Experts from the Austrian processing and recycling business were interviewed about the most important parameters of their quality inspection and how they affect the pricing policy. Additionally, quality parameters for input and output material are included. Besides the interviews, specific questions on correlations between the price and quality of cullets were e-mailed to several stakeholders in the glass industry. The main purpose of this paper was to identify the effects of different quality parameters on the pricing policy and how a benchmark is or can be defined. Experts from the glass processing industry did not confirm a correlation between price and quality, however: higher quality does not necessarily mean higher prices. Glassworks are ready to pay higher prices for higher qualities to meet their sustainability objectives or to expand their production capacities.
\end{abstract}

\section{INTRODUCTION}

Glass recycling is considered to be a vital step to the desired circular economy due to the special properties of glass. Those enable almost full recovery in recycling processes without any loss of material properties or quality (Aldrian et al., 2018).

Glass is an indispensable and well-integrated part of everyday life, whether in packaging or architecture and construction industry. In terms of sustainability, glass packaging is often preferred to plastic packaging. A study conducted by Neill and Williams in 2016 suggests that consumers are willing to pay more for reusable glass packaging (specifically milk bottles) if they believed them more environmentally friendly, whether they truly have a lower environmental impact or not. (Neill and Williams, 2016). The increased recycling rate required by the European Commission's circular economy package, up to $75 \%$ for glass packaging by 2030 , is no challenge for the local waste management as the current recycling rate in Austria is already well above this target (European Commission, 2019). A little more than half of Austria's glass production today (about $320.000 \mathrm{t}$ ) consists of glass packaging which translates to more than $257,000 \mathrm{t}$ substituted and therefore conserved primary materials. In 2017, the Austrian glass industry produced about 420,000 t of container glass, about 239,000 tonnes of which had been collected separated. The difference of 181,000 t can not be defined exactly. The Austrian glass industry is strongly based on export of container glass. Additionally, waste glass, which is disposed in the residual waste and not in the separate waste collection is also part of this difference (Austria Glas Recycling, 2020b). The collection volume of 239,000 $\mathrm{t}$ allows glass packaging produced in Austria to include an average of $2 / 3$ of waste glass. Furthermore, the production of glass in Austria mainly concerns packaging glass. A collection quota of $>80 \%$ is achieved, with respect to the 
data provided by 'Austria Glas Recycling' a company by ARA (Austria Glas Recycling, 2020a; BMLFUW, 2017; WKO, 2017). The recycling quota for glass packaging has been rising the last years to $84,1 \%$ in 2018 as well as the recovery quota to $88,4 \%$. These numbers are based on recycling and recycling in addition to energetic utilization, respectively (BMK, 2020). Meanwhile the average recycling quota of glass in the EU was around 70\% in 2017 (WKO, 2017).

Advantages of glass recycling are the reduced energy costs and emissions which lead to a more sustainable overall approach to packaging. For every $10 \%$ waste glass in glass packaging production the energy costs decrease by $3 \%$ and the $\mathrm{CO}_{2}$ emissions by $7 \%$. Pursuant to Art. 2 (4) of the Austrian Abfallwirtschaftsgesetz (AWG 2002), glass packaging is classified as waste requiring separate collection. In Austria, about 80,600 containers for both white and stained glass are provided for separate collection and since Austrian citizens have separated glass for over 40 years now the system is well integrated into society (BMNT, 2017; WKO, 2017).

In contrast to the limited use of plastic recyclates in new products, recycled glass is one of the most important components in producing glass packaging. Today, about $60 \%$ of new container glasses are made of recycled glass. Green container glass even contains up to $90 \%$ of recycled glass (Initiative der Glasrecycler im Aktionsforum Glasverpackung, 2019).

Recycling of separately collected waste, with glass being no exception, depends on the willingness of citizens to separate right at the source. The purer waste glass is separated, i. e. the less its colours are mixed by neglect or on purpose, the more cullets may be integrated into new container glass (Aldrian et al., 2018). The need for high quality is evident. Austrian legislation, however, does not stipulate any quality standards for waste glass or minimum requirements for oven-ready cullets.

With this paper the requirements for waste glass are being examined, the correlation between price and quality of waste glass and the quality benchmark is evaluated. In addition, quality requirements for input material and treated glass as well as minimum requirements for oven-ready cullets are included. The importance of quality control and its implementation is underlined, focussing on container glass as bottles, glass packaging and cosmetics glass fed into separate collection systems.

\section{METHODS}

A market analysis of glass cullets was conducted by the means of telephone calls or via e-mail to identify the quality benchmark in glass recyclates.

To analyse the correlation between price and quality, glass processing plants, glassworks, manufacturers of preparation equipment and associations dealing with glass recycling received a specially designed assessment guide as well as a request to provide any product specification sheets that are given to suppliers for i.e. flint, amber or green glass - preferably container glass.

For the telephone interviews, a specific questionnaire with open questions was designed to address the correlation between price and quality of waste glass cullets, targeting the following questions:

- Which types of waste glass are processed or used?

- Is there a way how to assess the composition of input and output flows?

- Which contaminants have to be removed and how is waste glass processed? What is the amount of impurities and its upper limit beyond which product quality and cost-effectiveness of the treatment are impaired?

- What are the quality requirements for the products and how is quality control performed?

- Which developments/trends can be identified and derived in the market for cullets?

- Which unexploited potentials are currently identified in the field of waste glass processing and recycling?

- How could the quality of the waste glass collection system be improved?

Stakeholders who were not reached by phone received compressed e-mail editions of the above questions, followed by additional questions or brief telephone calls if any uncertainties or significant new findings occurred.

In addition to the then following personal discussions with representatives of the companies listed above, the remaining German glass industry was approached with the following shortened version of the questionnaire above consisting of largely the same topics:

- Contaminants which are particularly troubling for the production process and their limits

- Quality control of the inputstream (How? Where? Which parameters? Limits?)

- Quality control of products and important parameters

- Correlation between price and quality of the waste glass cullet

Altogether, 15 different stakeholders of the glass industry responded whether via e-mail or telephone. Three phone calls were made, reaching two glassworks and one manufacturer of preparation equipment. About 30 e-mails were sent to glass-processing plants, glassworks, manufacturers of preparation equipment and glass recycling associations in the process, resulting in a return rate of approx. $45 \%$. In the end two glassworks, six glass-processing companies, one manufacturer of preparation equipment and three associations responded. Figure 1 shows the distribution of the consulted companies by stakeholder affiliation in the cullet industry. $40 \%$ of glass processing companies, $27 \%$ of glassworks, $20 \%$ of associations and $13 \%$ of manufacturers of preparation equipment participated in the survey. In the Appendix A the results of two telephone responses are listed, in Appendix $B$ the results of six e-mailed answers are shown. For the other received answers, the participants have not given their permission to publish their answers neither in public listing of the company, nor in anonymous way. 


\title{
List of surveyed companies by stakeholder affiliation in the cullet industry
}

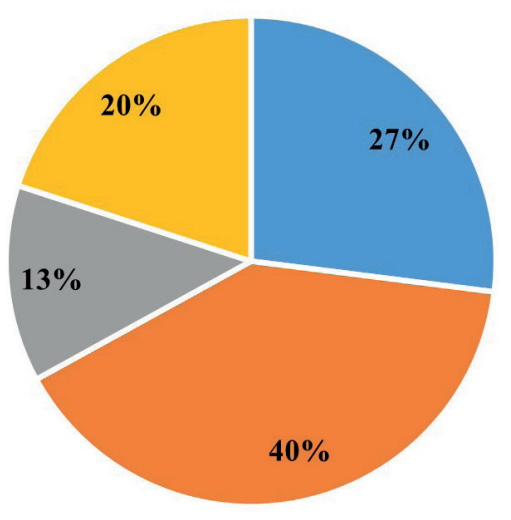

\author{
- Glassworks \\ - Glass processing companies \\ - Manufacturers of preparation equipment \\ - Associations and other stakeholders
}

FIGURE 1: The 15 surveyed companies by stakeholder affiliation in the cullet industry from Austria as well as Germany.

\section{RESULTS AND DISCUSSION}

\subsection{Quality requirements}

Currently, Austrian law does not stipulate any minimum quality specifications for waste glass to be used in the container glass industry or for oven-ready cullets. The Bundesverband Glasindustrie e.V. (BV Glas), the Bundesverband der Deutschen Entsorgungs-, Wasser- und Rohstoffwirtschaft e.V. (BDE) and the Bundesverband Sekundärrohstoffe und Entsorgung e.V. (BVSE) have jointly developed general specifications regarding the quality of waste glass and oven-ready cullets which are observed by all European glassworks. These associations have also tackled waste glass fed to processing plants and developed a technical specification for hollow glass, enforcing standardisation in glass recycling and glass processing. Additional agreements are made between waste glass processors and glassworks generally exacerbating the values defined in the 'Quality requirements for cullets to be used in the container glass industry' guideline T 120 or adding additional parameters. These strict requirements allow the glass industry to produce new products of consistent quality.

Below, the quality requirements for waste glass are described in more detail. Furthermore, the product specifications of hollow glass developed by the associations mentioned above are examined. Finally, the minimum quality specifications for oven-ready cullets are specified. The following descriptions refer to the source 'BDE (2019)' in the References.

\subsubsection{Product specifications for hollow glass}

Since this paper discusses container glass, the product specifications of hollow glass are given first. Contaminant limits and purities of the collected fractions are particularly emphasised because a certain purity of the fraction is essential for its use by glassworks. The following product specifications developed by the above mentioned associations apply:

- Product specification of collected hollow glass, type flint glass TR 201 (BVSE \& BDE, 2013a)
- Product specification of collected hollow glass, type green glass TR 202 (BVSE \& BDE, 2013b)

- Product specification of collected hollow glass, type amber glass TR 203 (BVSE \& BDE, 2013c)

- Product specification of collected hollow glass, type stained glass TR 204 (BVSE \& BDE, 2013d)

The product specification sheets refer to container glass such as bottles, jars, pharmaceutical and cosmetics glass from glass packaging collection points. A comparison of the listed product specification sheets is shown in Table 1.

3.1.2 Quality requirements for cullets used in the container glass industry

The following refers to the 'Quality requirements for cullets to be used in the container glass industry' guideline $T$ 120 (BV Glas et. al., 2014).

Container glass from households, industry and production such as bottles, jars, pharmaceutical and cosmetics glass (soda-lime glass) are included. With regard to the state of the art the following substances should not be included: lead glass, non-processed safety glass, glass ceramics, lighting glass, TV glass, quartz glass, borosilicate glass, other leaded glasses and all substances that may interfere with the melting and production process.

The quality of the processed cullets must be maintained during transport. For storage and delivery, ensuring that the processed cullets are not exposed to contamination is vital, including but not limited to suitably cleaned means of transport (e. g. lorries) and clean collection bins.

The 'Quality requirements for cullets to be used in the container glass industry' guideline T 120 (BV Glas et. al., 2014) is seen as the quality benchmark for cullets in the container glass industry by the surveyed companies.

\section{Maximum content of impurities}

The limits given in Table 2 represent monthly averages or averages of at least 250 tons of glass which should not be exceeded. All values are upper limits as stated in the T120 'Quality requirements for cullets to be used in the 
TABLE 1: Products specifications of hollow glass (BDE, 2019).

\begin{tabular}{|c|c|c|c|c|}
\hline & Flint glass $^{1}$ & Green glass $^{2}$ & Amber glass $^{3}$ & Stained glass ${ }^{4}$ \\
\hline $\begin{array}{l}\text { Purity in wt.\% } \\
\text { Glass according to the specified amounts of contami- } \\
\text { nation with other types of glass }\end{array}$ & $\begin{array}{l}\text { Min. } 97.00 \% \\
\text { Max. } 1.00 \% \\
\text { Max. } 2.00 \%\end{array}$ & $\begin{array}{l}\text { Min. } 97.00 \% \\
\text { Max. } 1.00 \% \\
\text { Max. } 2.00 \%\end{array}$ & $\begin{array}{l}\text { Min. } 97.00 \% \\
\text { Max. } 1.00 \% \\
\text { Max. } 2.00 \%\end{array}$ & $\begin{array}{l}\text { Min. } 97.00 \% \\
\text { Max. } 1.00 \% \\
\text { Max. } 2.00 \%\end{array}$ \\
\hline Amount of other coloured glass & $\begin{array}{l}\text { Max. } 3.00 \% \\
\text { Green: } 1.00 \% \\
\text { Amber: } 2.00 \%\end{array}$ & Max. $15.00 \%$ & Max. $15.00 \%$ & Max. $10.00 \%$ \\
\hline $\begin{array}{l}\text { Impurities } \\
\text { Maximum amount of impurities } \\
\text { (max. } 1 \% \text { in total) } \\
\text { Ceramics, stone, porcelain } \\
\text { Other waste (cans, plastics, cardboards) } \\
\text { Maximum amount of other types of glass } \\
\text { (max. } 2 \% \text { in total) }\end{array}$ & $0.15 \%$ & $\begin{array}{l}0.15 \% \\
0.10 \%\end{array}$ & $\begin{array}{l}0.15 \% \\
0.10 \%\end{array}$ & $\begin{array}{l}0.15 \% \\
0.10 \%\end{array}$ \\
\hline $\begin{array}{l}\text { Quartz glass } \\
\text { Borocsilicate glass } \\
\text { Glass ceramics } \\
\text { Glass from electronic equipment } \\
\text { Lead crystal glass } \\
\text { Wired glass } \\
\text { Car glass } \\
\text { Flat glass } \\
\text { Ampoules, injection glass }\end{array}$ & $\begin{array}{c}- \\
- \\
0.01 \% \\
0.005 \% \\
\\
0.01 \% \\
0.20 \% \\
0.20 \% \\
2.00 \% \\
2.00 \%\end{array}$ & $\begin{array}{c}- \\
- \\
0.01 \% \\
0.005 \% \\
\\
0.01 \% \\
0.20 \% \\
0.20 \% \\
2.00 \% \\
2.00 \%\end{array}$ & $\begin{array}{c}- \\
- \\
0.01 \% \\
0.005 \% \\
\\
0.01 \% \\
0.20 \% \\
0.20 \% \\
2.00 \% \\
2.00 \%\end{array}$ & $\begin{array}{c}- \\
- \\
0.01 \% \\
0.005 \% \\
\\
0.01 \% \\
0.20 \% \\
0.20 \% \\
2.00 \% \\
2.00 \%\end{array}$ \\
\hline
\end{tabular}

${ }_{1}^{1}$ Product specification of collected hollow glass, type flint glass TR 201 (BVSE \& BDE, 2013a)

2 Product specification of collected hollow glass, type green glass TR 202 (BVSE \& BDE, 2013b)

${ }_{3}^{3}$ Product specification of collected hollow glass, type amber glass TR 203 (BVSE \& BDE, 2013c)

${ }^{4}$ Product specification of collected hollow glass, type stained glass TR 204 (BVSE \& BDE, 2013d)

TABLE 2: Maximum content of impurities.

Ceramics
Non-ferrous metals
Ferrous metals

container glass industry'. Limits refer to flint, green, amber and stained container glass, respectively. (BDE, 2019)

\section{Ceramics, stone, porcelain (CSP)}

Avoiding a high CSP Value decreases the risk of explosions due to reactions of ceramics in the melt. The melting tank and process are very sensitive and precisely tailored to the mixture, fed via special feeding systems. Each tank is customised and adjusted to the requirements of the glassworks. However, due to their higher melting point, ceramics, stones and porcelain do not completely melt in the tank therefore they remain in the processed glass, creating inclusions.

These inclusions may cause a number of issues including breakage, defects and/or deformation of container glass. In addition, these visible defects cause rejection of the finished product. Therefore, the amount of reject increases at what is called the 'cold end' where each glass product is precisely measured and checked for faults using special inspection systems. If a defect is not detected, it may break at the bottler's, during transport or even at the end-consumers. With carbonated beverages, risk of breakage is particularly high (e. g. champagne bottles). Thus, in- clusions can be a safety-related defect since their degree of hardness will differ from that of glass, resulting in voltage differences which may ultimately cause the glass to burst.

\section{Metals (ferrous and non-ferrous)}

Due to the comparatively high melting temperatures of around $1,500-1,600{ }^{\circ} \mathrm{C}$ metals can cause various problems in the melting process. Long-term damage of the melting tanks is is one of them as the metals sink to the bottom of the tank and rotate there due to the flow of the refractory material. Additionally, damage to the bottom of the melting furnace may even be due to metals melting at lower temperatures, such as lead. Furthermore, metals that are hydrophobic to the refractory material, such as ferrous metals, may aggregate into a ball which can lead to a rotational movement causing holes in the bottom of the tank. Metal-stopping layers are used to prevent this kind of damage.

\section{Loose organics}

In general, loose organics cause carbon input. The presence of carbon is basically not a problem, but varying contents of carbon may constitute one. If the content is too 
high, colours may begin to drift, causing large-scale production losses or deviations from the colour specifications of the customers. Carbon triggers an oxidative process in the melt that may cause the colour of the glass to change, especially with flint glass that may then be tainted grey or yellow. On the other hand, excessive or irregular accumulation of organics on the surface of the melt may cause foaming or blistering. When the molten material is surface-fired, too little heat is induced by the foam barrier. The result is irregular melting, higher energy input and/or longer residence times of the material in the melting tank. In extreme cases, nests from slightly molten glass material may arise.

The limits set to loose organics have several arguments. For energetic and environmental reasons, melting tanks are now operated with very small excessive air. Organic content influences this residual oxygen content. Therefore, in practical application, recycled waste glass is stored for about six weeks before it is mixed with molten glass, to avoid any influence of organics (fermentation).

Moreover, loose organics have a tendency of fine pieces of broken glass adhering to them. Due to their high organic content, these fine shards often cannot be completely used as secondary raw materials so that the recycling rate for waste glass will fall short of $100 \%$ (Aldrian et. al., 2018).

\section{Moisture}

Moisture is of particular importance for the sorting and preparation of waste glass. If the moisture content is too high, the cullets are difficult to screen and the quality of sensor-based sorting will suffer significantly. As a result, a constant transport speed on slides can no longer be guaranteed. If a cullet is slowed down during the sliding process by an 'adhesive' water film on the chute in the detection unit, it can no longer be blown away by compressed air in the separator on time.

On the one hand the limit to moisture is set to avoid excessive variations, on the other hand for the treatment process, a certain amount of moisture is beneficial in preventing dusting and segregation. However, this moisture must be evaporated and therefore should be kept at a minimum.

\section{Heavy metals}

Since glass can be melted again and again, there is still a lot of 'vintage' glass participating in the circulation, melted before lead-sorting equipment had been installed and the limits had been in place. This 'vintage' glass still contains a lot of lead which is slowly reduced by dilution processes. Lead was once used to increase the gloss of the glass (up to $35 \%$ of lead oxide ( $\mathrm{PbO})$ ). During melting, evaporation may be significant in regard to environmental limits. However, exceptions are sometimes made to permit higher emission limits. Heavy metals basically do not affect material properties or consistency.

This limit is rather politically motivated, driven by the limitation of heavy metals established in the plastics industry. In fact, there is no elution from glass, but consumers prefer glass without heavy metals. Of course, accumulation of heavy metals in glass containers is undesirable. For example, basic contaminations of approx. 200 ppm of lead oxide $(\mathrm{PbO})$ are already present in new bottles imported from Asia according to one of our interviewees. In addition, the glassworks are subject to legal stipulations which should not be violated by the use of recycling cullets. For example, Art. 4 (1) of the Austrian Verpackungsverordnung of 2014 states that packaging with a concentration exceeding 100 ppm by weight of lead, cadmium, mercury and chromium (VI) is prohibited unless lead crystal is concerned (Verpackungsverordnung, 2014).

Experts from waste-glass processing have supported restrictions concerning lead in packaging i.e.

For the discharge of lead-containing materials, a lot of equipment is already installed. Cullets containing lead oxide are detected by optoelectronic devices, such as UV cameras.

\section{Heat-resistant glass}

Contamination of the ember stream with heat-resistant glass prevents the cutter from working properly. The finished conditioned glass is shaped into gobs by the feeder machine and then cut by a scissors mechanism at the end of the drop-forming process. If larger melting relics pieces of CSP or refractory materials - should occur here, the droplet cannot be properly cut, disrupting therefore the production process. Heat-resistant glass and glass ceramics are hard to detect at the input controls of glassworks, requiring appropriate sorting equipment in waste-glass processing. Glassworks and waste-glass processors are well equipped with sorting units detecting and separating heat-resistant glass.

A limit value for heat-resistant glass is given in the specification sheet 'T120' under the item 'Glass-ceramic'. A separation quality of at least $90 \%$ on the part of the system manufacturer is required to avoid the presence of these materials in the ember stream. Most European glassworks tolerate a maximum concentration of $25 \mathrm{~g} / \mathrm{t}$ of refractory cullets in the ready-to-melt product.

\section{Content of other coloured glass (incoming)}

The colour is determined in the grain band $>8 \mathrm{~mm}$ square mesh. The maximum contents of other colours for the glass types flint, green, amber and stained are listed in Table 3.

\subsubsection{Requirement for oven-ready cullets}

The 'Minimum quality specification of oven-ready cullets' guideline TR 310 regulates the standards for the glass industry (BVSE \& BDE, 2013e).

Container glass from households, trade and production is considered. The processing plant must be operated with appropriate technology such as sensor based sorting equipment for dealing with contaminants to comply with the quality criteria of oven-ready cullets as defined in Table 4.

The 'Minimum quality specification of oven-ready cullets' guideline TR 310 is seen as the quality benchmark for over-ready cullets by the surveyed companies.

\subsection{Quality control}

The applying quality requirements for separately collected waste glass have already been mentioned in the previous section. The Austrian and German industry com- 
TABLE 3: Maximum contents of other colours for specific glass types (BDE, 2019).

\begin{tabular}{|c|c|c|c|c|}
\hline & Flint glass ${ }^{1}$ & Green glass $^{2}$ & Amber glass $^{3}$ & Stained glass \\
\hline Colour amber & $\leq 0.3 \%$ & Max. $10.0 \%$ & Min. $80.0 \%$ & Min $80.0 \%$ \\
\hline Colour green & $\leq 0.2 \%$ & Min. $75.0 \%$ & Max. $10.0 \%$ & Min $80.0 \%$ \\
\hline Other colours & $\leq 0.2 \%$ & - & - & - \\
\hline
\end{tabular}

${ }^{1}$ Transition colours from white to green, acid-green and half-white, are white.

${ }^{2}$ All shades of green including the reduced shades of green are considered green.

Cullets in the range of $568 \mathrm{~nm}$ to $573 \mathrm{~nm}$ are considered reduced green hues.

${ }^{3}$ All shades of amber are considered amber.

TABLE 4: Requirements for oven-ready cullets (BDE, 2019).

\begin{tabular}{l|l}
\hline Ferrous metals & $\leq 50 \mathrm{ppm}$ \\
\hline Non-ferrous metals & $\leq 60 \mathrm{ppm}$ \\
\hline Inorganic non-metallic, non-glass materials like ceramics, stones, porcelain or pyroceramics: & $\leq 100 \mathrm{ppm}$ \\
$\cdot$ Cullets $>1 \mathrm{~mm}$ & $\leq 1,500 \mathrm{ppm}$ \\
- Cullets $\leq 1 \mathrm{~mm}$ & $<2,000 \mathrm{ppm}$ \\
\hline Organic impurities like paper, rubber, plstics, fabric or wood & \\
\hline
\end{tabular}

ply with the guidelines of the Bundesverband Glasindustrie e.V. (BV Glas), the Bundesverband der Deutschen Entsorgungs-, Wasser- und Rohstoffwirtschaft e.V. (BDE) and the Bundesverband Sekundärrohstoffe und Entsorgung e.V. (BVSE) since there are no uniform quality standards. The parameters CSP (ceramics, stones, porcelain), ferrous and non-ferrous metals as well as heat-resistant glasses are essential when assessing the quality of cullets. As these materials have different melting temperatures to glass, they do not (completely) melt in the melting tank, causing inclusions and, hence, production problems. In addition to these parameters, the content of lead-containing glass, the organic content and the fine-grain content are important for assessing the quality of the cullet.

Input material is visually controlled by material acceptance staff. Based on their experience and expertise, the quality of the glass fragments can be assessed by paying attention to the load of undesired impurities such as residual waste, wood and CSP. In case of suspicion, lead glass is checked with an ultraviolet lamp. Quality control in laboratories is not an option for real input quantities, owing to the high amounts passing per day. Hollow glass usually derives from colour-separated collection. The main focus is on the degree of refraction of the cullets and contamination of the loading surface by subcharge, such as gravel. An essential part of input control is the colour distribution of the bulk material since mono-coloured waste glass is a much better secondary raw material than multi-coloured glass. (BVSE, 2019). Stained glass would lead to discoloration in white glass (BMNT, 2017). In addition, empirical data show that waste glass fractions in certain regions (for example, in large cities) have a lower quality meaning lower purity.

Basically, the following stages of quality control are mentioned by the industry partners participating in this study after the processing of waste glass:

- The plant operator trusts his plant and no quality control is performed.

- There is a continuous sampling in the output stream of the treatment plant. The following parameters are checked in the laboratory:

- colour purity,

- impurities and

- chemical composition.

- Semi-automated sampling is performed. Continuously sampled material enters an analyser running semi-automated analyses or protocols. A plausibility check made by laboratory staff is not rendered obsolete that way.

Quality control by sensor-based machines is still rarely met, though demand by industry is rising.

\subsection{Sampling of recycled glass}

Sampling may be performed before delivery of the cullets or sent by the supplier beforehand. Consequently, a representative sample volume is taken, analysed and if it complies with stipulated limits the total amount will be delivered. No further sampling is then required upon receiving the goods, thus saving time. The Bundesverband Sekundärrohstoffe und Entsorgung e.V. (BVSE) and the Bundesverband der Deutschen Entsorgungs-, Wasser- und Rohstoffwirtschaft e.V. (BDE) have jointly developed a guideline for standardised sampling of cullets to ensure reproducible measurement results: 'Sampling for the use in the container glass industry' TR 101 (BVSE \& BDE, 2013f).

\subsection{Market study}

\subsection{Pricing structure}

The market price for waste glass is primarily based on geographic conditions as mentioned by some of the interview partners. The following questions are significant: Where does the cullet come from? Where does the cullet go? Furthermore, the market price includes collection, processing and transport and is based on the primary raw material and the amount of energy consumed by processing. There are no parameters defining the purity of waste glass.

The following factors are mentioned as essential by the surveyed companies:

- Price for quartz sand/soda/lime, 
TABLE 5: Prices for recycled cullets (BDE, 2019).

\begin{tabular}{c|c|c} 
Glass type & Price range & Price variation \\
\hline Flint glass & $€ 85,-$ to $90, / \mathrm{t}$ & $+/-€ 10,-/ \mathrm{t}$ \\
Amber glass & $€ 85,-$ to $90, / \mathrm{t}$ & $+/-€ 10,-/ \mathrm{t}$ \\
\hline Green glass & $€ 65,-$ to $70, . / \mathrm{t}$ & $+/-€ 10,-/ \mathrm{t}$ \\
\hline Stained glass & $€ 40,-$ to $50, / \mathrm{t}$ & $+/-€ 5,-/ \mathrm{t}$ \\
\hline
\end{tabular}

- transport of the cullets to the treatment plant,

treatment efforts,

- energy drawback from using primary raw materials in the melt and

- transport of cullets to the glassworks.

Usually, the glassworks negotiate prices with the suppliers 'delivered to the delivery point' so that the material price for waste glass will vary with the site of the processing plant and the distance to the glassworks. The prices presented in Table 5 are currently observed in Austria (recycled waste glass) by two industry interview partners although it was mentioned more than once that those can vary and are therefore to be taken with a grain of salt. Others would not want to mention numbers precisely because of these concerns.

The interviewed container-glass processing experts have claimed that prices indicated in the table above are currently tolerable. They mentioned, however, that the pricing may also turn unfavourable; for example, the price for a tonne of waste glass may drop to $€ 20$,-. The experts agreed on the other hand that any price above $€ 100,-/ t$ was hard to achieve. Moreover, prices for waste glass are generally declining due to decreasing expenses for energy investments into production.

Observations in Germany show that the price of waste glass can vary due to geographical conditions. In the south there is an excess of white glass, but fewer glassworks are established. On the contrary in the north there are many glassworks and a high demand for white glass. Therefore, the price of white glass is higher in northern Germany than in the south. Prices for green glass are distributed exactly the other way round: In the north, there is an excess of green glass, in the south there is a great demand for it. One reason for this discrepancy may be found in the brewing industry located in Bavaria. Hence, the price of green glass is higher in southern Germany than in the north.

Figure 2 shows the development of the price in euros pro ton for processed cullets. It can be seen that the price for class cullets per ton since 2002 until 2019 has continuously risen as proven by the data from EUROSTAT (2020) and WIFO (2016), although a slight drop can be observed between 2008 and 2011 which is probably caused by the world economy crisis. The price for each individual color of cullets is decreasing over the years. These data are specifically from the UK (WRAP.ORG.UK, 2008) and show a different trend than the data from EUROSTAT (2020) and WIFO (2020).

In Figure 3 the price development of the primary resources for glass production is shown. For the composition of glass, a mixture of $20 \%$ soda ash and limestone respectively and $60 \%$ sand has been used to calculate the price per ton using individual statistics for each primary re-

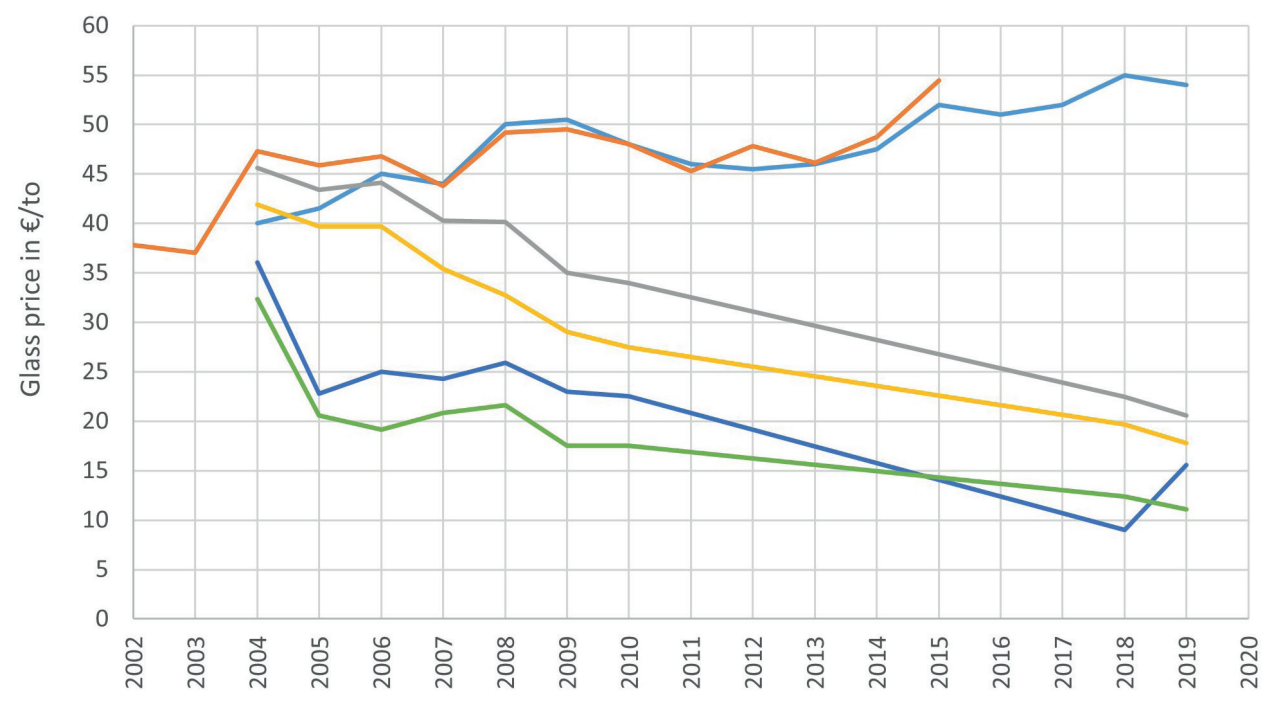

$\begin{array}{ll}\text { EUROSTAT } & \text { WIFO } \\ \text { WRAP.ORG.UK amber glass } \longrightarrow \text { WRAP.ORG.UK green glass } \longrightarrow \text { WRAP.ORG.UK mixed glass }\end{array}$

FIGURE 2: Price development for processed cullets. 
source. However, no reliable data could be found for the primary resources other than sand. The price for sand is stable throughout the years starting from 2008. For the price per ton of limestone a drastic increase can be observed starting from 2014. The price per ton for soda ash is the highest out of the mixture ranging from $220 € / t$ to $280 € / t$ and peaking in 2018. The calculated price per ton of glass produced from primary resources starting from 2016 shows a slight increase of about $10 € / t$ through the time frame 2016 until 2019 while being in the range of 60 $70 € / t$, compared to $50-60 € / t$ for class cullets in the same time frame.

\subsubsection{Correlation: price and quality}

Quality does not really affect pricing policies. All suppliers face the same specifications (usually 'Quality requirements for cullets to be used in the container glass industry' T 120). This quality must be achieved in any case. Basically, higher quality of the input material does not result in a higher price: a delivery of qualities below the specified limit values is accepted but not separately priced. Exceeding the limits will cause rejection of the delivery. Waste glass recyclers will pay more for waste glass that is less contaminated because subsequent treatment will be less expensive. However, the main part of recycled waste glass from licensed collection systems is paid a standard price.

The surveyed companies observe the following relationships between price and quality:

- One is described like this: If the glassworks expands its processing and requires more waste glass, it is likely to pay a better price.

- Another is described like this: Companies are endeavoring to use cullets to produce new glass which also affects the pricing policy and results in toleration of higher prices. Their sustainability strategies pursue the goal of using a high relative amount of waste glass in their new production. The purer the cullets, the more of them can be added to the melt. The higher the amount of cullets, the lower the impact on the environment.

In Austria, prices for waste glass are subject to supply and demand as in the general market mechanism. Higher quality does not need to be more expensive. Occasionally, special glassworks producing cosmetics glass or high-quality bottles will pay higher prices for clear glass. In general, however, prices for cullets have reached a point at which the use of primary raw materials may become economically feasible again.

\subsection{Quality benchmark in glass recycling}

The conducted market analysis did not provide any information on a benchmark for cullets. Producers of waste glass were therefore asked to identify one. For input materials, the quality standard, which is seen as quality benchmark, used by the industry is the 'Quality requirements for cullets to be used in the container glass industry' guideline $\mathrm{T}$ 120. Besides, the Bundesverband Glasindustrie e.V. (BV Glas), the Bundesverband der Deutschen Entsorgungs-, Wasser- und Rohstoffwirtschaft e.V. (BDE) and the Bundesverband Sekundärrohstoffe und Entsorgung e.V. (BVSE) have jointly developed general specifications regarding the quality of waste glass and oven-ready cullets. The 'Minimum quality specification of oven-ready cullets' guideline TR 310, which is seen as the quality benchmark for overready cullets, is observed by all European glassworks.

\section{CONCLUSIONS}

Whether there is a correlation between price and qual-

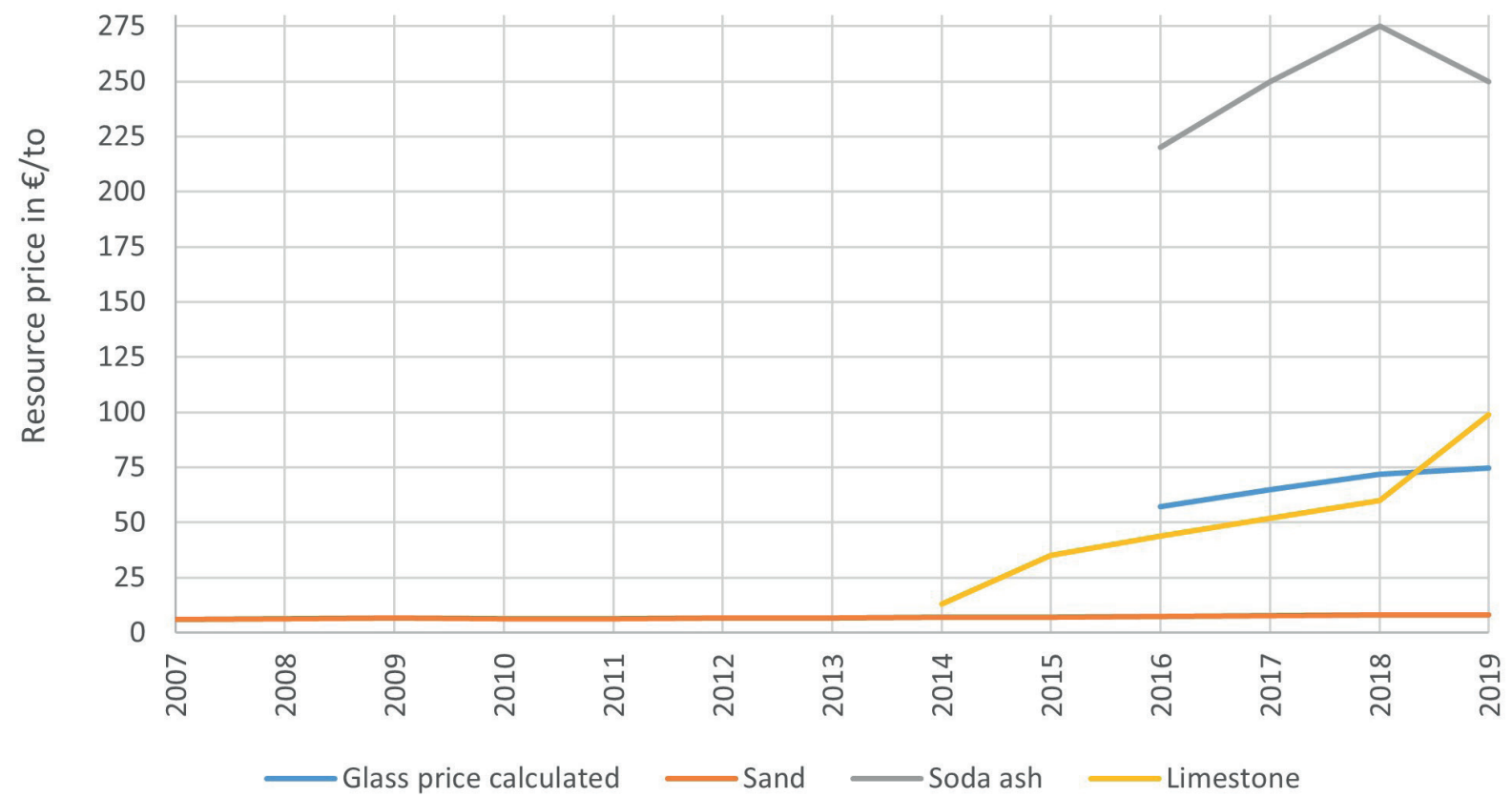

FIGURE 3: Price development of the primary resources for glass production. 
ity of waste glass could not be conclusively determined. The interviewed experts from the container glass industry do not perceive an interaction of these two parameters. It could merely be perceived that a higher price for better quality will be paid if a company intends to use a high content of cullets in production to achieve sustainability or higher capacity. Therefore, the price of waste glass emerges primarily from the equilibrium of supply and demand on the general market. Furthermore, the costs for collecting waste glass, processing cullets and transporting to the glassworks enter calculations. Waste glass is naturally priced based on the price of primary raw materials and energy consumption during processing. The market price for waste glass also varies by location of the processing plant and distance to the glassworks.

Quality inspection of waste glass is usually executed by material acceptance staff. Based on empirical values, reliable assessment of the quality of delivered glass waste can be expected. This assessment is compelling for further processing. The parameters 'CSP' (ceramics, stones, porcelain), ferrous and non-ferrous metals as well as heat-resistant glass severely impact the quality of cullets. In addition to these parameters, staff consider the content of lead-containing glass, organics content and fine-grain content when assessing the quality of waste glass.

Currently, there is no minimum quality stipulated in Austria for waste glass applied by the container glass industry or for oven-ready cullets. The Bundesverband Glasindustrie e.V. (BV Glas), the Bundesverband der Deutschen Entsorgungs-, Wasser- und Rohstoffwirtschaft e.V. (BDE) and the Bundesverband Sekundärrohstoffe und Entsorgung e.V. (BVSE) have jointly developed general specifications regarding the quality of waste glass and oven-ready cullets, which set the quality benchmark in the glass industry. The agreed upon specifications are respected by all European glassworks. Therefore, the great goal of standardisation of quality requirements in glass recycling and glass processing was reached, which enabled the industry to produce while achieving consistent quality.

Finally, the use of waste glass in container glass production can be considered essential and furthermore called the most important raw material for new production. In recent years the use of waste glass was considerably and successfully pushed by waste glass processors, manufacturers of preparation equipment and glassworks. However, an important part of achieving waste glass quality happens at the source, where the willingness of citizens to separate different types of glass decides whether high-quality container glass can be produced from recycled waste glass.

\section{REFERENCES}

Abfallwirtschaftsgesetz (AWG), 2002: Bundesgesetz über eine nachhaltige Abfallwirtschaft (Austrian federal act for sustainable waste management). BGBI. I Nr. 102/2002. RIS (Law information service Austria): (accessed on 06 August 2019).

Aldrian, A., Pomberger, R., Schipfer, C., Gattermayer, K., 2018. Altglasrecycling - Anteil an Störstoffen im Altglas in Österreich (Recycling of waste glass - Amount of impurities in waste glass in Austria). In: Pomberger et al. (eds.) (2018) Conference Proceedings for the Recy\&DepoTech Conference November 2018, Leoben. p. 193-198.
Austria Glas Recycling, 2020a: Austria Glas Recycling Website. Available online at https://www.agr.at/, checked on 7/9/2020.

Austria Glas Recycling, 2020b: Information received via e-mail from Austria Glas Recyclings Support on 14 August 2020.

Bundesverband der Deutschen Entsorgungs-, Wasser- und Rohstoffwirtschaft e.V. (BDE), 2019. Klare Regeln und anerkannte Standards stärken das Recycling von Altglas (Precise rules and recognised standards strengthen the recycling of waste glass). https:// bde.de/themen/kreislaufwirtschaft/glasrecycling (accessed on 06 August 2019).

Bundesministerium für Klimaschutz, Umwelt, Energie, Mobilität, Innovation und Technologie (BMK), 2020: Die Bestandsaufnahme der Abfallwirtschaft in Österreich Statusbericht 2020 (Referenzjahr 2018) (Inventory of Waste Management in Austria Status Report 2020 (Reference year 2018)).

Bundesministerium für Land- und Forstwirtschaft, Umwelt und Wasserwirtschaft (BMLFUW) (2017): Bundes-Abfallwirtschaftsplan 2017, Teil 1 (Austrian National Waste Management Plan 2017, Part 1).

Bundesministerium für Nachhaltigkeit und Tourismus (BMNT), 2017. Bundesabfallwirtschaftsplan 2017 (National waste economic guide 2017). ISBN: 978-3-903129-32-0. December 2017. Vienna, Austria.

Bundesverband Glasindustrie e.V. (BV Glas), Bundesverband der Deutschen Entsorgungs-, Wasser- und Rohstoffwirtschaft e.V. (BDE), Bundesverband Sekundärrohstoffe und Entsorgung e.V. (BVSE), 2014. Standard sheet T 120. Leitlinie ,Qualitätsanforderungen an Glasscherben zum Einsatz in der Behälterglasindustrie' (Guideline ,Quality requirements for cullets to be used in the container glass industry'). Edition: 25 March 2013.

Bundesverband Sekundärrohstoffe und Entsorgung e.V. (BVSE), 2019. Hoher Reinheitsgrad erforderlich (High purity required). https:// www.bvse.de/glasrecycling/themen/hoher-reinheitsgrad-erforderlich.html (accessed on 06 August 2019).

Bundesverband Sekundärrohstoffe und Entsorgung e.V. (BVSE), Bundesverband der Deutschen Entsorgungs-, Wasser- und Rohstoffwirtschaft e.V. (BDE), 2013a. TR 201. Produktspezifikation Sammelware Hohlglas Weiss (Product specification of collected hollow glass, type flint glass). Edition: 25 March 2013.

Bundesverband Sekundärrohstoffe und Entsorgung e.V. (BVSE), Bundesverband der Deutschen Entsorgungs-, Wasser- und Rohstoffwirtschaft e.V. (BDE), 2013b. TR 202. Produktspezifikation Sammelware Hohlglas Grün (Product specification of collected hollow glass, type green glass). Edition: 25 March 2013.

Bundesverband Sekundärrohstoffe und Entsorgung e.V. (BVSE), Bundesverband der Deutschen Entsorgungs-, Wasser- und Rohstoffwirtschaft e.V. (BDE), 2013c. TR 203. Produktspezifikation Sammelware Hohlglas Braun (Product specification of collected hollow glass, type amber glass). Edition: 25 March 2013.

Bundesverband Sekundärrohstoffe und Entsorgung e.V. (BVSE), Bundesverband der Deutschen Entsorgungs-, Wasser- und Rohstoffwirtschaft e.V. (BDE), 2013d. TR 204. Produktspezifikation Sammelware Hohlglas Bunt (Product specification of collected hollow glass, type stained glass). Edition: 25 March 2013.

Bundesverband Sekundärrohstoffe und Entsorgung e.V. (BVSE), Bundesverband der Deutschen Entsorgungs-, Wasser- und Rohstoffwirtschaft e.V. (BDE), 2013e. TR 310. Mindestqualitätsvorgabe 'ofenfertige Glasscherben' (Minimum quality specification of oven-ready cullets). Edition: 25 March 2013.

Bundesverband Sekundärrohstoffe und Entsorgung e.V. (BVSE), Bundesverband der Deutschen Entsorgungs-, Wasser- und Rohstoffwirtschaft e.V. (BDE), 2013f. TR 101. Leitlinie ,Qualitätsanforderungen an Glasscherben zum Einsatz in der Behälterglasindustrie' (Guideline: ,Sampling of cullets for usage in the container glass industry'). Edition: 25 March 2013.

European Commission, 2019. Circular Economy, Implementation of the Circular Economy Action Plan, http://ec.europa.eu/environment/ circular-economy/index_en.htm (accessed on 06 August 2019).

EUROSTAT, 2020: Price indicator and trade volume for waste glass, EU-27. https://ec.europa.eu/eurostat/statistics-explained/index. php?title=File:Price_indicator_and_trade_volume_for_waste_ glass,_EU-27.png (accessed on 14 August 2020).

Initiative der Glasrecycler im Aktionsforum Glasverpackung, 2019. Richtig Glasrecyceln (Correct glass recycling). https://www.waspasst-ins-altglas.de/richtig-glasrecyceln (accessed on 06 August 2019). 
Österreichisches Institut für Wirtschaftsforschung (WIFO), 2016: Volkswirtschaftliche Effekte durch Recycling ausgewählter Altstoffe und Abfälle (Economic effects of recycling specific waste and scraps).

Neill, C.L.; Williams, R.B., 2016: Consumer Preference for alternative milk packaging: The case of an inferred environmental attribute. In J. Agric. Appl. Econ. 48 (3), pp. 241-256. DOI: 10.1017/ aae.2016.17

Verpackungsverordnung, 2014. Verordnung des Bundesministers für Land- und Forstwirtschaft, Umwelt und Wasserwirtschaft über die Vermeidung und Verwertung von Verpackungsabfällen und bestimmten Warenresten (Directive of the Federal Minister for Agriculture, Forestry, Environment and Water Management on the prevention and recycling of packaging waste and certain remnants of goods). BGBI. II Nr. 184/2014. RIS (Law information service Austria): (accessed on 06 August 2019).
Waste and Resources Action Programme (WRAP.ORG.UK) (2008): Realising the value of recovered glass: An update, Market Situation Report. September 2008.

Wirtschaftskammer Österreich - Fachverband der Glasindustrie (WKO), 2017. Jahresbericht 2017 (Annual report 2017). https://www.wko. at/branchen/industrie/glasindustrie/jahresbericht-glasindustrie-2017.pdf (accessed on 06 August 2019)

\section{APPENDIX A: LISTS OF INTERVIEW RESULTS}

\section{How is the price for glass cullets determined?}

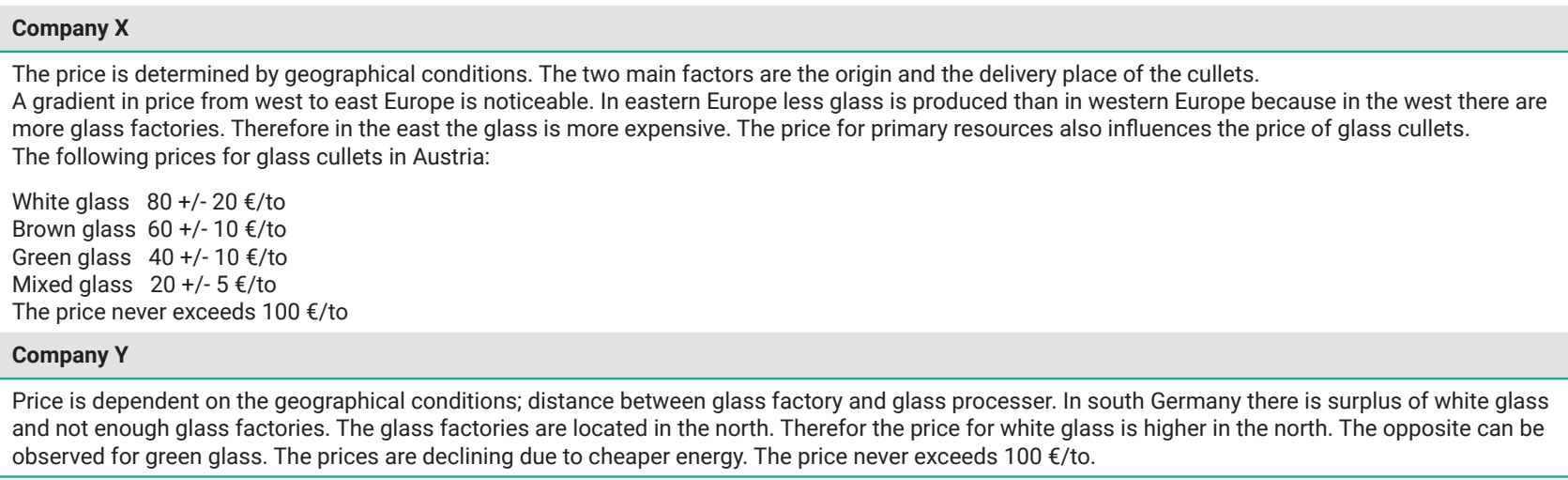

\section{What is the coherence between price and quality?}

\section{Company $\mathrm{X}$}

The goal is to use as many glass cullets as possible for glass production. The melting facility benefits form the usage of glass cullets as lower temperatures are sufficient in comparison to melting primary resources. For high quality cullets the prices is higher.

\section{Company $Y$}

Glass cullets with a high purity are more expensive than cullets with a lower purity. The main amount of processed glass originates from licensed collection systems and the price for that is uniform.

\section{How is the quality of glass cullets determined? Which parameters are essential?}

Company X

\section{Company $Y$}

On site. Parameters are: CSP, colour distribution, impurities

\section{Additional information}

\section{Company $\mathrm{X}$}

Porcelain can influence the form stability of the container glass because it does not fully melt. This leads to bubbles and inclusions on the surface of the container glass.

White glass: the content of iron has to be kept low to achieve the white colour

Green glass: the content of iron needs to be high for the colour. It consists of $80 \%$ waste glass and $20 \%$ primary resources. The melting temperature in the melting facility is $1.600{ }^{\circ} \mathrm{C}$. Around $50 \%$ of energy can be saved due to the lower melting point of glass cullets in comparison to primary resources. The retention time is 24 hours. The finished bottles are analysed by a computer after cooling.

Company $Y$ 


\section{APPENDIX B: Lists of results to the e-mailed questions}

1. Which impurities are especially problematic for the molten glass? What are the limit values for these impurities?

Company A
The quality parameters for waste container glass cullets are CSP, purity and color distribution. They are evaluated on site (not in a separate laboratory).
Company B

An important parameter that is being analysed is the content of ceramics.

Company C

Limit values for glass (TA 120 germany); the following values do not apply for special glasses (heat resistant glass etc.)

CSP $20 \mathrm{~g} / \mathrm{to}$

Metall $5 \mathrm{~g} / \mathrm{to}$

Organics $400 \mathrm{~g} / \mathrm{to}$

PBO 200 ppm

Colored class in white glass $0-6$

Company D

In Germany general quality agreements for glass between three economical bonds (BDE, BVSE and BV Glas) exist. Additional quality standards exist between waste glass processing companies and glass factories (e.g. the guidline TA 120 "quality requirements for glass cullets for usage in container glass industry").

The following quality parameters are essential: CSP, metals, heat resistant glass, lead glass, organics and fine-grained material.

A high content of the first three parameters causes production problematics and inclusion due to their higher melting point. The content of lead glass causes a high lead content in the produced container glass (limit value for lead in packaging material). Organics and fine-grained material cause problems in the controlling aspect of the process.

Company E

The input material ( 600 to/d) is visually analysed for impurities.

Company $\mathbf{F}$

\begin{tabular}{|c|c|c|c|c|c|c|c|c|c|c|c|c|c|c|c|}
\hline \multicolumn{16}{|c|}{ Parameter } \\
\hline \multirow{2}{*}{$\begin{array}{c}\text { Quality parameter } \\
\text { Glass type }\end{array}$} & \multicolumn{3}{|c|}{ Ceramics/Porcelain in g/to } & \multicolumn{3}{|c|}{$\mathrm{FE}$ in $\mathrm{g} /$ to } & \multicolumn{3}{|c|}{$\mathrm{NE}$ in $\mathrm{g} /$ to } & \multicolumn{3}{|c|}{ Stones in $\mathrm{g} /$ to } & \multicolumn{3}{|c|}{ Organics in g/to } \\
\hline & $\min$ & $\max$ & tol. & $\min$ & $\max$ & tol. & $\min$ & $\max$ & tol. & $\min$ & $\max$ & tol. & $\min$ & $\max$ & tol. \\
\hline green & 0 & 10 & +5 & 0 & 5 & +3 & 0 & 5 & +3 & 0 & 30 & +10 & 0 & 1000 & +500 \\
\hline white & 0 & 10 & +5 & 0 & 5 & +3 & 0 & 5 & +3 & 0 & 30 & +10 & 0 & 1000 & +500 \\
\hline
\end{tabular}

2. How is the quality of the glass cullets evaluated? Which parameters are analysed?

Company A

They are evaluated on site (not in a separate laboratory).

Company B

The cullets are either being analysed when delivered or directly at the supplier to save time during the delivery. The delivered cullets are not accepted in the case of insufficient quality.

\section{Company $\mathrm{C}$}

Limit values for glass (TA 120 germany); the following values do not apply for special glasses (heat resistant glass etc.)

CSP $20 \mathrm{~g} / \mathrm{to}$

Metall $5 \mathrm{~g} /$ to

Organics $400 \mathrm{~g} / \mathrm{to}$

PBO 200 ppm

Colored class in white glass $0-6$

Company D

In Germany general quality agreements for glass between three economical bonds (BDE, BVSE and BV Glas) exist. Additional quality standards exist between waste glass processing companies and glass factories (e.g. the guidline TA 120 "quality requirements for glass cullets for usage in container glass industry").

The following quality parameters are essential: CSP, metals, heat resistant glass, lead glass, organics and fine-grained material.

Company E

The input material ( 600 to/d) is visually analysed for impurities.

Company $\mathbf{F}$ 
3. How is the price for processed glass cullets determined? Which parameters are essential??

\section{Company A}

The price is determined by the purity and the cost for transportation. A high purity causes a high price.

Company B

The produced container glass is continuously analysed by machines and humans. One important parameter that is being analysed is the content of ceramics.

The price for cullets is determined by supply and demand; the quality is secondary.

White glass: ca. $85-90 € /$ to

Brown glass: ca. $85-90 € /$ to

Green Glass: ca. $65-70 € /$ to

Mixed glass cullets are not being used in Germany; prices never exceed $100 € /$ ton

\section{Company C}

Buying price is determined by the costs for collection, processing and transport; quality parameters are not considered. On delivery samples are taken and analysed (e.g. lead glass is detected by using a UV-lamp)

Selling price is not generally determined by CSP content. The selling price for processed cullets is at a point at which the usage of primary resources might be more beneficial.

White glass: ca. $85-90 € /$ to

Brown glass: ca. $85-90 € /$ to

Green Glass: ca. $65-70 € /$ to

Processing costs are around $20-30 € /$ to

\section{Company D}

Selling price is not determined by quality, though the requirements are set in the TA 120 . The material is not accepted by the glass factory if these require ments are not fulfilled.

The price is also dependent on the distance between glass factory and glass processer

Processing cost are around $30 € /$ to.

Company E

The price for cullets are negotiable. High purities lead to higher prices.

Company $\mathbf{F}$

4. What is the coherence between price and quality of glass cullets?

\begin{tabular}{l} 
Company A \\
\hline A high purity causes a high price. \\
Company B \\
\hline The price for cullets is determined by supply and demand; the quality is secondary. \\
Company C \\
\hline Selling price is not generally determined by CSP content. \\
\hline Company $\mathbf{D}$ \\
\hline The price is also dependent on the distance between glass factory and glass processer. \\
\hline Company $\mathbf{E}$ \\
\hline The price for cullets are negotiable. High purities lead to higher prices. \\
Company $\mathbf{F}$ \\
\hline -
\end{tabular}

